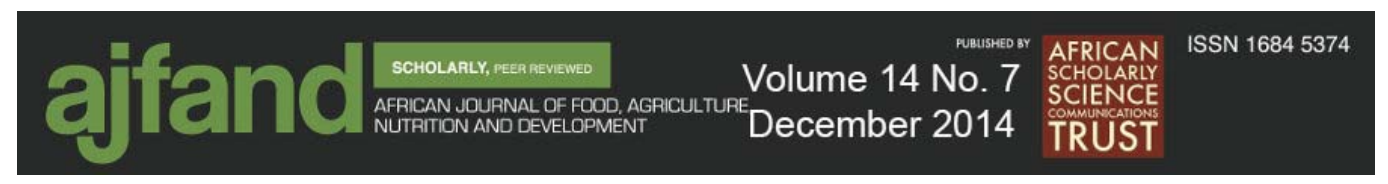

\title{
NUTRITIONAL QUALITY, PHYTOCHEMICAL COMPOSITION AND HEALTH PROTECTIVE EFFECTS OF AN UNDER-UTILIZED PRICKLY CACTUS FRUIT (OPUNTIA STRICTA HAW.) COLLECTED FROM KENYA
}

Kunyanga $\mathrm{CN}^{1^{*}}$, Vellingiri $\mathrm{V}^{2}$ and $\mathrm{KJ}$ Imungi ${ }^{1}$

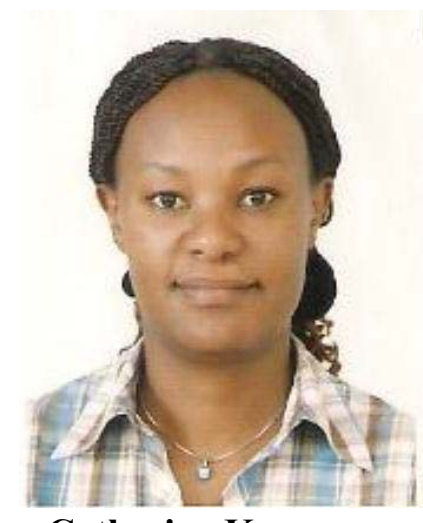

Catherine Kunyanga

*Corresponding author email: ckunyanga@uonbi.ac.ke

${ }^{1}$ Department of Food Science, Nutrition and Technology, University of Nairobi, Kenya

${ }^{2}$ Institute of Oenology and Food Engineering, Universita Cattolica Del Sacro Cuore, Piacenza, Italy. 


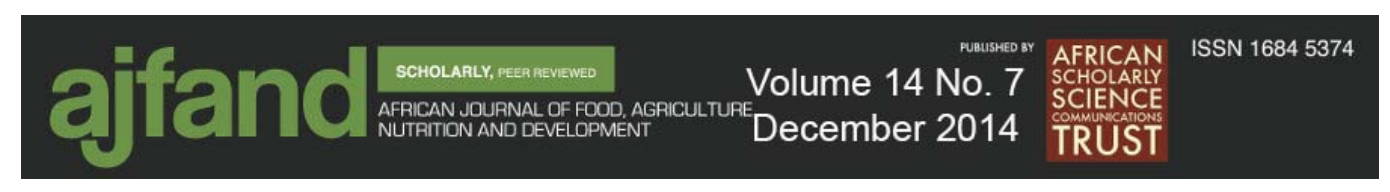

\begin{abstract}
The cactus fruit belongs to the Cactaceae family and is native to the arid and semi-arid regions of the world, where the production of more succulent food plants is severely limited. Opuntia stricta Haw, fruits have recently invaded the harsh dry rangelands of the Laikipia Plateau of North-eastern Kenya. These cactus fruits contribute immensely to the nutrition and food security needs of humans living in Laikipia. Despite the health benefits of these fruits, the cactus plant faces the possibility of extinction due to adverse effects of the prickly fruit when ingested by the livestock belonging to the local communities in Laikipia. The present study, therefore, was designed to assess the chemical composition, bioactive compounds and their health promoting properties in Opuntia stricta cactus fruits. The results showed that the cactus pulp is a rich source of ascorbic acid (60 mg/100 g), minerals (622 mg/kg P, $12.8 \mathrm{mg} / \mathrm{kg} \mathrm{Ca}, 38 \mathrm{mg} / \mathrm{kg} \mathrm{Fe}$ and $91 \mathrm{mg} / \mathrm{kg} \mathrm{Na}$ ), and sugars (18.5 mg sucrose, $10.9 \mathrm{mg}$ glucose and $6.9 \mathrm{mg}$ fructose). The seeds contained significant amount of protein $(4.13 \%)$, oil $(11.5 \%)$, fibre $(12.3 \%), \beta-$ carotene $(56 \mu \mathrm{g} / 100 \mathrm{~g})$ and total carotenoids $(289 \mu \mathrm{g} / 100 \mathrm{~g})$. The seed oil contained high levels of linoleic (70\%), palmitic (12.5\%) and stearic $(12.3 \%)$ acids. The main fatty acids were linoleic, oleic, palmitic and stearic acids with high unsaturation level $(83 \%)$. The principal amino acids in the fruits were arginine, tyrosine, glutamic acid, proline and aspartic acid. The cactus whole fruits exhibited remarkable levels of total phenols (1.6 g/100g), flavonoids (197 mg/100g), tannins $(1.5 \mathrm{~g} / 100 \mathrm{~g})$ and phytates $(2.6$ $\mathrm{g} / 100 \mathrm{~g})$. The phytochemical extracts demonstrated high antioxidant activity in terms of FRAP assay (1.2-6.9 $\mu \mathrm{g} / \mathrm{mM}$ Fe (II) reducing power) and DPPH assay (73-86\%). The anti-diabetic effect of the extracts showed strong inhibition $(>50 \%)$ of $\alpha$-glucosidase as compared to the $\alpha$-amylase inhibition. Thus, consumption of $O$. stricta fruits could meet the key nutritional requirements and help to address the double burden of food insecurity and chronic diseases among communities living in the drylands of Kenya. The results of this study could help inform the public on the nutritional and health benefits of the Opuntia cactus fruit and address issues raised by the media on the possible eradication of cactus plants in Laikipia and other drylands regions of Kenya.
\end{abstract}

Key words: Opuntia stricta, bioactive compounds, antioxidants, diabetes 


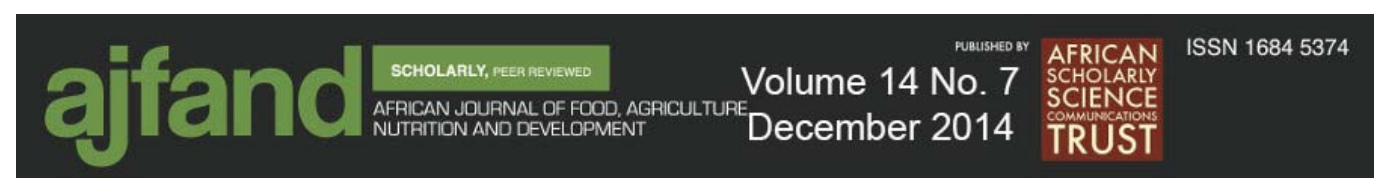

\section{INTRODUCTION}

Plants in the genus Opuntia are members of the Cactaceae family that is widely distributed in arid and semi-arid regions throughout the world [1]. Among the members of this family, Opuntia ficus-indica is the largest genus and most widespread species that has been successively cultivated in semi-arid regions of the world for commercial processing $[2,3]$. The cactus plant originated from tropical America and its fruits are widely consumed as a delicacy in northern Mexico, South-western United States, Mediterranean countries and South Africa $[4,5,6]$. Cactus plants can grow under harsh conditions and have low water exigency and a high water-use efficiency ratio, which makes it suitable for extensive production as underlined by the Food and Agriculture Organization [7]. The annual production of cactus fruit is in the range of 50 tons/hectare under optimum conditions [8]. In the last few years, cactus fruits have become an important crop in arid and semi-arid regions, where they play a strategic role in rural agriculture. In Kenya, efforts are currently being made to prevent the eradication of this plant that grows under wild conditions for future fruit production and new applications in the food industries.

The cactus plants are characterized by a huge diversity with relation to their parts including the fruit and exhibit great variability in chemical composition $[9,10]$. The skin and pulp colour, pulp texture, sugar content, and juice acidity of cactus fruits are directly related to the presence, intensity and activity of nutritional and functional compounds [11]. The nutritional and phytochemical composition of different species of cactus fruit have been studied $[4,5,8,10,12]$. The presence of phytochemicals in cactus fruits varieties have been linked to their antioxidant, anti-inflammatory, anticancer, antiviral, analgesic, anti-LDL cholesterol peroxidation, hypoglycemic and antimicrobial activities $[2,3,9,10,13]$.

An invasive species of cactus, Opuntia stricta Haw, is growing wildly throughout the arid and semi-arid regions of Kenya. The fresh fruits (cactus pear) are consumed exclusively by humans, livestock and wild animals. The fruit is fleshy, varying in shape, size and colour, with a number of hard seeds. Consequently, cactus pear has become an important fruit for conservation and food security in the arid and semi-arid regions of Kenya, where the production of more succulent food plants is severely limited [14]. To the best of our knowledge, the chemical composition and functional properties of Opuntia stricta fruits growing in Kenya have not yet been investigated. Despite the limited research studies on this Opuntia spp., it has formed an important source of food and feed in the drylands of Laikipia plateau of Northern Kenya. In addition, high consumption of the cactus prickly fruit in the rural communities living in arid and semiarid regions makes it interesting to evaluate the nutritional and health promoting aspects of this fruit. Therefore the current study was designed to investigate the nutritional contents, bioactive compounds, antioxidant and anti-diabetic properties of Opuntia stricta fruits. 


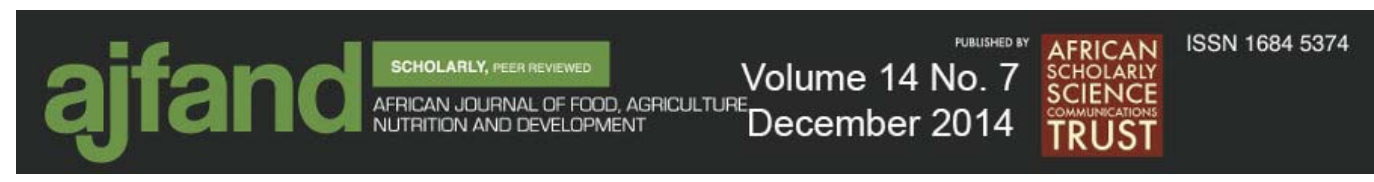

\section{MATERIALS AND METHODS}

\section{Sample collection}

Well ripened Opuntia stricta fruits were harvested from the wild in Laikipia plateau, Northeastern Kenya. These materials were quickly transported to the laboratory and placed in a cold room. The fruits of the same size and ripening stage, free from damage were selected for analysis. One portion of the fruit samples was separated into peel, pulp tissue and seeds for chemical analysis, while the rest of the whole fruits were dried and used for mineral and phytochemical analysis. Both whole fruits and fractions (peel, pulp and seeds) were dried in hot-air oven at $50^{\circ} \mathrm{C}$ for $6 \mathrm{~h}$ and milled using a laboratory mill (Hammer mill, type DFH48, No. 282521/UPM 6000, Switzerland) and then sieved $(0.1 \mathrm{~mm})$ to obtain a fine powder for biochemical analysis.

\section{Biochemical composition}

The fruit components (pulp, peel and seeds) were analyzed for chemical composition. Nitrogen (960.52), ether extract (920.85), ash (923.03), moisture content (934.01), and fibre (991.43) were determined according to the standard methods of AOAC [15]. The remaining percentage was represented as carbohydrates by difference. Energy was calculated from fat, carbohydrate and protein contents using Atwater's conversion factors. Ascorbic acid was determined following the AOAC [15] official method 967.21 for fruits by titration with the 2-6 dichlorophenol-indophenol reagent. The total and reducing sugars were determined by the Munson-Walker method [15] and some individual sugars by HPLC, equipped with a 6000A pump, RI 400 detector and Sugarpack column (Waters Corporation, USA) at $90^{\circ} \mathrm{C}$, using EDTA-Ca $50 \mathrm{ppm}$ aqueous solution. Total carotenoids and $\beta$-carotene were also analyzed according to standards methods of AOAC [15].

Mineral constituents (calcium, iron, magnesium, potassium, phosphorus, sodium, and zinc) of whole and dried fruit samples were determined using inductively coupled argon plasma atomic emission spectroscopy (ICP-AES, Jarrel-Ash). The amino acid profile was determined according to standard methods of the Official Journal of the European Union.

The amino acids were separated by ion exchange chromatography and determined by reaction with ninhydrin using photometric detection at $570 \mathrm{~nm}$ (440 $\mathrm{nm}$ for proline). The amino acids and internal standards were measured using an amino acid analyzer (Eppendorf-Biotronic LC 3000, LaborserviceOnken, 63584 Gründau, Germany).

The ground seeds were extracted with petroleum ether $\left(\mathrm{Bp} 80^{\circ} \mathrm{C}\right)$ for 16 hours to obtain oil to be used for fatty acid analysis of the seeds. The fatty acid methyl esters (FAME) were analyzed using Hewlett-Packard HP 5911A mass spectrometer interfaced with an HP 5890 gas chromatograph. Electron ionization at $70 \mathrm{eV}$ with an ion source temperature of $240^{\circ} \mathrm{C}$ was used. An HP-5 column was used $(30 \mathrm{~m}$ x $0.25 \mathrm{~mm}$ i.d; film thickness $0.25 \mu \mathrm{m}$ ), with helium carrier gas. The oven temperatures were $70-325^{\circ} \mathrm{C}$ and $0.2 \mu \mathrm{l}$ of the diluted fatty acid esters were injected into the GC-MS. The fatty acids were 


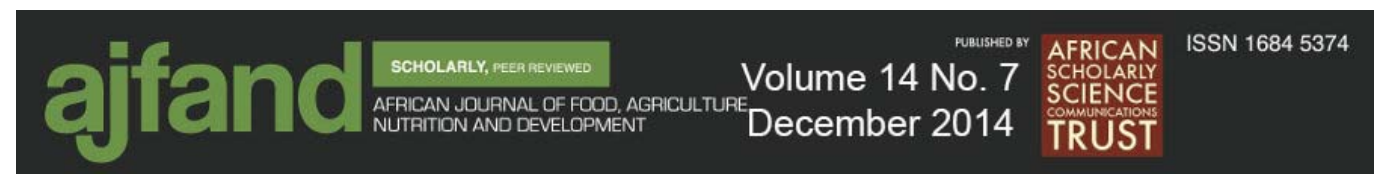

identified by comparing the retention time of FAME with the standard 37 component FAME mixture or relative to authentic standards.

\section{Phytochemical compounds}

The whole fruit samples were defatted by adding petroleum ether in 1:10 ratio (W/V) and kept in an ultrasonic bath for $30 \mathrm{~min}$. After centrifugation at 13,000 rpm for $5 \mathrm{~min}$, the residue was collected and air-dried. The defatted samples were extracted by using $50 \%$ aqueous ethanol for the flavonoid analysis; $70 \%$ acetone for the condensed tannins; $1 \% \mathrm{HCl}$-methanol for the total phenolics and $2.4 \% \mathrm{HCl}$ for phytic acid for 30 min in an ultrasonic bath and then centrifuged at 13,000 rpm for $5 \mathrm{~min}$. Prior to evaporation, the methanolic extract was purified by treating with $1 \mathrm{~g}$ of polyvinylpolypyrolidone (PVPP) at $0^{\circ} \mathrm{C}$ for $30 \mathrm{~min}$ and Solid Phase Cartridge (Strata$\mathrm{x}-33 \mu \mathrm{m}$ polymeric sorbent, 8B-S100-FCH-S, Phenomenex, Aschaffenburg, Germany). The acetonic extract was also purified using Sephadex LH-20 column chromatography. The phytic acid extract was purified using an anionic-exchange column chromatography $(0.7 \mathrm{~cm} \times 15 \mathrm{~cm})$ containing $0.5 \mathrm{~g}$ of anion-exchange resin (100-200 mesh, chloride form; AG1-X4, Bio-Rad Co., CA, USA). All the solvents were then evaporated using a rotary vacuum evaporator (Büchi Rotavapor, $\mathrm{CH}-9230$, Büchi Labortechnik GmbH, Essen, Germany) at $40^{\circ} \mathrm{C}$, frozen overnight at $-80^{\circ} \mathrm{C}$ and dried in lyophilizer (Virtis Freezemobile 25 EL, New York) and finally the residues were re-dissolved in appropriate solvents.

Total phenolics were estimated using Folin-Ciocalteu reagent [16]. Based on the standard curve prepared with $(+)$-catechin hydrate $(20-100 \mu \mathrm{g})$, the amount of total phenolics in the extract was calculated. The analysis of flavonoids was performed according to the spectrophotometric method adapted from Jia et al. [17]. (+) Quercetin $(20-120 \mu \mathrm{g})$ calibration curve was used to calculate the amount of flavonoids. The condensed tannins were quantified using modified vanillin- $\mathrm{HCl}$ reagent method [18]. Phytic acid was estimated according to Latta and Eskin [19] using the standard curve prepared with synthetic sodium phytate and expressed as $\mathrm{g} / 100 \mathrm{~g}$ on dry weight basis.

\section{Functional properties}

The antioxidant activity of different phytochemical extracts were analyzed in terms of 2,2'-Diphenyl-1-picryl hydrazyl (DPPH) radical scavenging activity and ferric reducing/antioxidant power (FRAP) by following the methods of Sanchez-Moreno et al. [20] and Pulido et al. [21], respectively. Inhibition of $\alpha$-amylase and $\alpha$-glucosidase enzyme activities by different phytochemical extracts was measured by following the method of Worthington [22].

\section{Statistical analysis}

All data were analyzed and expressed as mean and standard error of three separate determinations. The means were tested for significance differences using the Turkey's test. The statistical analysis was carried out using GraphPad PRISM ${ }^{\circledR}$ version IV software, San Diego, CA. Means between the groups were compared using ANOVA and $p<0.05$ was considered as statistically significant. 


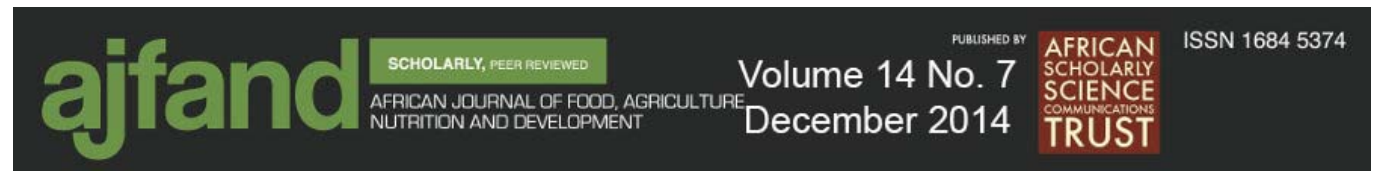

\section{RESULTS}

\section{Chemical characteristics and nutrient profile}

The cactus pear fruit may be separated into three fractions for commercial processing i.e. seeds, peel and pulp. The seeds constitute $10-15 \%$ of the edible pulp and are usually eaten together with the pulp. Table 1 shows the caloric value and chemical composition of the Opuntia stricta fruits. The chemical composition of the peels, pulp and seeds of the fruit indicating that seeds have highly significant level of proteins, oil, fiber and carotenoids as compared to the pulp and peel. Opuntia stricta fruits exhibited high ascorbic acid content $(60 \mathrm{mg} / 100 \mathrm{~g}$ in the peel and $57 \mathrm{mg} / 100 \mathrm{~g}$ in the pulp). The $O$. stricta fruits contained high levels of total carotenoids $(34-289 \mu \mathrm{g} / 100 \mathrm{~g})$ and $\beta$-carotene $(18 \mu \mathrm{g} / 100 \mathrm{~g})$. Opuntia stricta fruit also exhibited sucrose as the predominant sugar in the pulp $(18.5 \mathrm{mg} / \mathrm{ml})$ followed by glucose $(10.9 \mathrm{mg} / \mathrm{ml})$ and fructose $(6.9 \mathrm{mg} / \mathrm{ml})$.

The mineral composition of whole and dried fruits of $O$. stricta is shown in Table 2 . The cactus fruit in the present study contained high levels of phosphorus $(62.2 \mathrm{mg} / 100$ $\mathrm{g})$, sodium $(9.1 \mathrm{mg} / 100 \mathrm{~g})$, calcium $(1.18-1.28 \mathrm{mg} / 100 \mathrm{~g})$, iron $(3.0-3.8 \mathrm{mg} / 100 \mathrm{~g})$ and potassium $(45-47 \mathrm{mg} / 100 \mathrm{~g})$.

\section{Amino acid and fatty acid composition}

The amino acid contents of $O$. stricta fruit are shown in Table 3. The levels of the predominant amino acids detected in the Opuntia cactus fruit investigated in the present study were arginine $(0.14 \%)$, tyrosine $(0.12 \%)$, glutamic acid $(0.12 \%)$, proline $(0.09 \%)$ and aspartic acid $(0.09 \%)$.

The fatty acid profile of the seed oil from cactus (Opuntia stricta Haw.) is shown in Table 3. The profile of the seed oil indicates that the lipids from the cactus are a good source of the nutritionally essential linoleic acid and the unsaturated oleic acid. The ratio of linoleic acid to oleic acid was about 5:1. The predominant fatty acid was linoleic acid (69.5\%), followed by palmitic acid (12.5\%) and oleic acid (12.3\%).

The unsaturated fatty acids (oleic, linoleic, $\alpha$-linolenic and arachidonic fatty acid) fraction of seed oil was found to be predominant (82.9\%). Palmitic and stearic acids were the major saturated fatty acids found in the seed oil which represented $17 \%$ of the total fatty acids.

\section{Phytochemical compounds}

In addition to the major food constituents such as proteins, fat, carbohydrates and micronutrients, cactus fruits contain other non-nutritive components that may have positive effect on human health. Table 4 shows the levels of bioactive compounds of Opuntia stricta Haw whole fruits. The total phenol content of Opuntia stricta fruit was found to be $1.58 \mathrm{~g} / 100 \mathrm{~g}$. The presently analyzed Opuntia stricta fruits recorded a remarkable amount of flavonoids $(196.7 \mathrm{mg} / 100 \mathrm{~g})$. To the best of our knowledge, no studies have reported the tannin content in Opuntia cactus fruits. Tannins are a unique group of water-soluble phenolic metabolites of relatively high molecular weight. Currently there is an increasing interest in tannins as bioactive component of foods as 


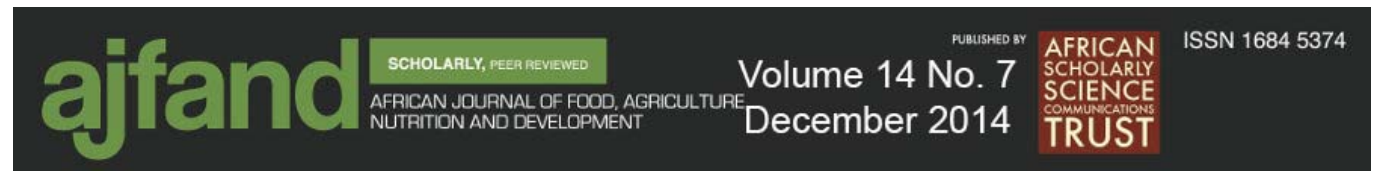

well as biological antioxidants. The phytic acid content of $O$. stricta fruit investigated in this study was $2.59 \mathrm{~g} / 100 \mathrm{~g}$.

\section{Antioxidant activity}

The Ferric Reducing Antioxidant Power values (FRAP) of different phytochemical extracts of Opuntia stricta fruit are illustrated in Table 4. Since the results are calculated on the basis of amount of phytochemical extract required to reduce one millimole of $\mathrm{Fe}$ (III) to Fe (II), the lowest value has highest antioxidant power. The flavonoid extract $(1.22 \mu \mathrm{g} / \mathrm{mM}$ Fe II) exhibited significantly higher antioxidant activity than those of phenolic, tannin and phytate extracts.

The DPPH free-radical scavenging activity of the extracts of Opuntia stricta fruits are shown in Table 4 . The results show tannins and phytate extracts have significantly high antioxidant activity than phenolic and flavonoid extracts and comparable to that of the synthetic antioxidant, BHT (97\%).

\section{Anti-diabetic activity}

The $\alpha$-amylase and $\alpha$-glucosidase inhibition activity of the extracts from $O$. stricta are shown in Table 5. Among the extracts, high level of $\alpha$-amylase inhibition was noted in phenolics (17\%), while no inhibition was observed in flavonoids and tannin extracts. Phytate extract exhibited $\alpha$-amylase enzyme inhibition of $15.67 \%$, which is comparable to acarbose, a commercial drug used in the clinical management of diabetes (15.6\%) $(23,24)$.

Strong inhibition ( $>50 \%$ ) of $\alpha$-glucosidase was noted in extracts of tannin $(95.67 \%)$, phenolic $(79 \%)$ and phytate $(65 \%)$ while the flavonoids extracts exhibited low inhibition $(36.67 \%)$.

\section{DISCUSSION}

Fruits such as the cactus prickly pear can be consumed as a source of carbohydrates, minerals and vitamins. The chemical composition of the Opuntia spp., in the present study is comparable to that of reported for other cactus pear fruit varieties in ascorbic acid (20-40 $\mathrm{mg})$, protein $(0.7 \mathrm{~g})$, fats $(0.5 \mathrm{~g})$, glucose $(7.8 \mathrm{~g})$, and minerals for $100 \mathrm{~g}$ edible portion [23]. Studies on the chemical components present in cactus pear pulp of other Opuntia cactus species such as Opuntia ficus-indica have also been reported to contain $0.2-1.6 \%$ protein, $0.09-0.7 \%$ fat, $0.02-3.15 \%$ fibre, and $0.4-1 \%$ ash [24]. The peels of the cactus fruit investigated in this study were considerably high in fibre (7.74\%). The beneficial effects of fibre in human health have been shown to act together with other bioactive compounds in the prevention of chronic diseases [4]. A wide range of ascorbic acid contents have been reported for different Opuntia species and varieties corresponding to $0.121-0.815 \mathrm{mg} / \mathrm{g}[2,10]$. Opuntia fruit of the current study showed a carbohydrate content of $7.9 \%$, which corresponds to $35 \mathrm{kcal}$ in the pulp which would provide more than half the daily requirement. A review in 2005 recommends a daily consumption of 2-4 servings of fruits to provide approximately $70 \mathrm{kcal}$ or $15 \mathrm{~g}$ of carbohydrates/serving [25]. 
Similar mineral contents as observed in this cactus spp have been reported in other cactus pear fruit species which were reported to contain high levels of potassium (12.8$27.6 \mathrm{mg} / 100 \mathrm{~g})$, calcium $(15.4-32.8 \mathrm{mg} / 100 \mathrm{~g})$ and magnesium $(98.4 \mathrm{mg} / 100 \mathrm{~g})$, whereas levels of sodium, iron, and phosphorus are in the typical range of fruits [24]. Calcium and phosphorus represent three-quarters of the minerals in the body and are found fundamentally in bones, which serve as an important reservoir. The consumption of cactus fruits can help alleviate micronutrient deficiencies, which is a major burden among people in Kenya. Major micronutrient deficiencies include iodine deficiency disorder, iron deficiency anaemia, and vitamin A and zinc deficiency, with high rates among young children. Approximately $25 \%$ of children are iodine deficient, although rates of goitre have significantly reduced from $16 \%$ (1994) to 6\% (2004) due to the near universal household consumption of iodized salt [26].

Similar amino acid composition as observed in O. stricta under study have been reported in bacuri (Platonia insignis Mart.), cupuacu (Theabroma grandiflorum Willd ex-Spreng Schum) and murici (Byrsonima crassifolici L.) fruits which were also shown to have high levels of glutamic acid $(46.6 \mathrm{mg} / \mathrm{kg})$, aspartic acid $(28.8 \mathrm{mg} / \mathrm{kg}$ ) and arginine $(25.3 \mathrm{mg} / \mathrm{kg})$ amino acids [27]. However, the amino acid profiles of the cactus fruit of the current study was lower than the FAO/WHO [28] reference pattern, but this fruit can be used in combination with other protein foods to achieve the amino acids requirement level.

The data on fatty acid composition of $O$. stricta is in agreement with previous reports on cactus seed oil from Opuntia ficus-indica $L$. which showed a similar trend wherein linoleic acid was the fatty acid marker [8]. The lipid pattern of $O$. stricta seed oil is comparable with that of sunflower and grapeseed oils [29]. Linolenic acid content $(0.7 \%)$ was lower than the linoleic acid $(70 \%)$ in the cactus seeds. These unique properties of the fatty acid components in the cactus seed oil have immense positive nutritional impact on the health condition of its consumers.

The presence of phenolic compounds in fruit samples of cactus pears have been reported by Kuti [10]. In a previous study, the flavonoid content of Opuntia dillenii was reported as $32 \mathrm{mg} / 100 \mathrm{~g}$ in the peel, $29 \mathrm{mg} / 100 \mathrm{~g}$ in the pulp and $144 \mathrm{mg} / 100 \mathrm{~g}$ in the seeds [9]. Little is known about the flavonoid content of Opuntia stricta and other under-utilized fruits from developing countries like Kenya. Recent studies on indigenous foods showed that the tannins are present in high levels in many plant foods and play a key role in the functional properties of the food [30]. Hence, presence of appreciable amounts of condensed tannin $(1.50 \mathrm{~g} / 100 \mathrm{~g})$ in the presently studied fruit indicates that these compounds are of great importance in the health promoting properties of the fruit. Previous studies also indicate that phytic acid occurs in various foods including fruits at different concentrations ranging from 0.1 to $6.0 \mathrm{~g} / 100 \mathrm{~g}$ [31]. However, limited studies have been done on the phytic content of Opuntia species.

The ferric reducing power of the phytic acid extracted from $O$. stricta fruits investigated in this study was $4.83 \mu \mathrm{g} / \mathrm{mM}$ Fe (II). Phytic acid forms an iron chelate, which 


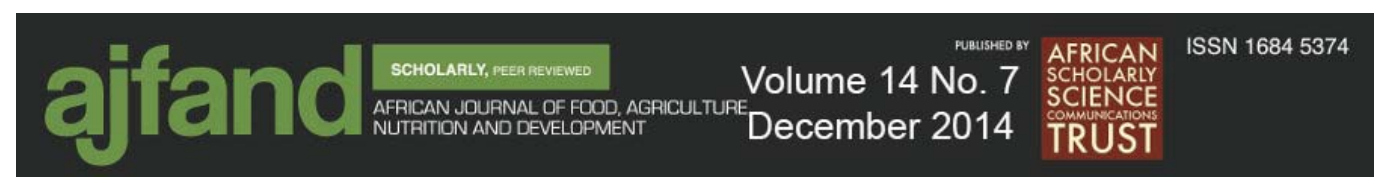

accelerates $\mathrm{Fe}^{2+}$-mediated oxygen reduction yet blocks iron-driven hydroxyl radical generation and suppresses lipid peroxidation. Therefore, phytic acid may supply an important antioxidant function by its metal binding characteristics. The high antioxidant values in the tannins and phytates extracts are in agreement with similar observations that have described tannins as superior antioxidant [30]. Similarly, the ability of phytic acid extracted from the cactus fruits in the present study to scavenge the stable synthetic DPPH free radical was quite exceptional $(86 \%)$.

Partial inhibition of activity of $\alpha$-amylase and $\alpha$-glucosidase enzymes lead to lowered sugar absorption and consequently useful for the management of blood sugar levels in hyperglycaemia and type II diabetic subjects [30,31]. All the extracts showed much stronger inhibition of $\alpha$-glucosidase than that observed for $\alpha$-amylase. Similar observations were reported by Kuti [10] in berry cactus (Myrtillocactus geometrizans) fruits. The $\alpha$-glucosidase inhibition activity of tannin extract was significantly higher $(p<0.05)$ than that of other extracts. Such promising inhibitory activity of tannin extracts from $O$. stricta on the $\alpha$-glucosidase enzyme could be the focus of future attention in the management of Type II diabetes mellitus for people living in harsh environments. The extent of inhibition of $\alpha$-glucosidase demonstrated by phytate extract is directly related to their high phytic acid content $(2.59 \mathrm{~g} / 100 \mathrm{~g})$ which may prove to be synergistic in their potential therapeutic effect on post-meal blood glucose level. These results are based on in vitro biochemical tests and are indicative of antiglycemic effects in the prevention/management of type II diabetes. To the best of the researchers' knowledge, this is the first preliminary study reporting the $\alpha$-glucosidase inhibition activity by these cactus fruits, and further extensive investigation is necessary in this aspect.

\section{CONCLUSION}

These results indicate that the fruits of Opuntia stricta Haw are an important source of fibre, essential oil, vitamins and minerals for the vulnerable groups living in these harsh conditions of Kenya where most diets are plant-based hence posing high risks of deficit in growth and development. Studies on the bioactive compounds and their functional properties showed their potential health benefits in synergistic action. This research investigation revealed the nutraceutical potential of Opuntia stricta cactus fruits collected from Kenya and opens new agricultural and industrial prospects that warrants further studies for its economic utility in functional and therapeutic foods.

\section{ACKNOWLEDGEMENT}

The authors are thankful to the German Academic Exchange Services (DAAD) for financial support of the first author's Doctoral study in Kenya. 


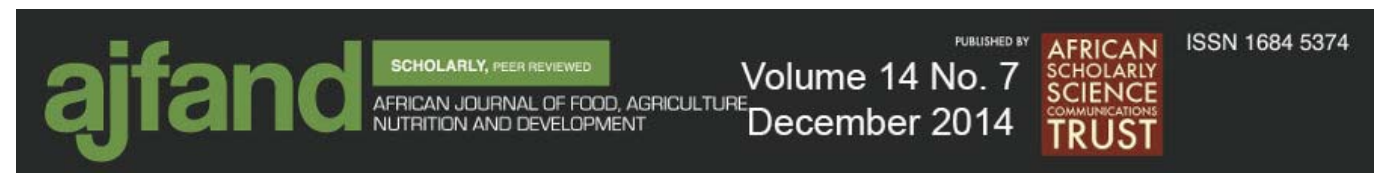

Table 1: Chemical composition of cactus fruits (Opuntia stricta) ${ }^{1,2,3,4}$

\begin{tabular}{lccc}
\hline Chemical composition & Peel & Pulp & Seeds \\
\hline Moisture content $(\%)$ & $81.73^{\mathrm{a}} \pm 0.25$ & $90.34^{\mathrm{a}} \pm 0.56$ & $66.02^{\mathrm{a}} \pm 0.45$ \\
Total minerals $(\%)$ & $2.90^{\mathrm{a}} \pm 0.16$ & $0.61^{\mathrm{a}} \pm 0.00$ & $1.71^{\mathrm{a}} \pm 0.16$ \\
Protein $(\%)$ & $0.80^{\mathrm{a}} \pm 0.01$ & $0.83^{\mathrm{a}} \pm 0.02$ & $4.13^{\mathrm{b}} \pm 0.01$ \\
Oil content $(\%)$ & $0.42^{\mathrm{a}} \pm 0.07$ & $0.21^{\mathrm{a}} \pm 0.05$ & $11.50^{\mathrm{b}} \pm 0.03$ \\
Total fiber $(\%)$ & $7.74^{\mathrm{a}} \pm 0.15$ & $1.32^{\mathrm{b}} \pm 0.01$ & $12.31^{\mathrm{c}} \pm 0.34$ \\
Carbohydrates $(\%)$ & $7.21^{\mathrm{a}} \pm 0.33$ & $7.91^{\mathrm{a}} \pm 0.22$ & $9.24^{\mathrm{a}} \pm 0.25$ \\
Energy $(\mathrm{Kcal} / 100 \mathrm{~g})$ & $35.37^{\mathrm{a}} \pm 0.24$ & $35.09^{\mathrm{a}} \pm 0.46$ & $43.05^{\mathrm{a}} \pm 0.16$ \\
Sucrose $(\mathrm{mg} / \mathrm{ml})$ & $7.31^{\mathrm{a}} \pm 0.01$ & $18.50^{\mathrm{b}} \pm 0.13$ & $9.11^{\mathrm{a}} \pm 0.30$ \\
Fructose $(\mathrm{mg} / \mathrm{ml})$ & $5.52^{\mathrm{a}} \pm 0.00$ & $6.93^{\mathrm{a}} \pm 0.41$ & $2.82^{\mathrm{a}} \pm 0.02$ \\
Glucose$(\mathrm{mg} / \mathrm{ml})$ & $7.87^{\mathrm{a}} \pm 0.12$ & $10.91^{\mathrm{a}} \pm 0.01$ & $2.13^{\mathrm{a}} \pm 0.40$ \\
Total caretonoids $(\mu \mathrm{g} / 100 \mathrm{~g})$ & $7.06^{\mathrm{a}} \pm 0.53$ & $34.21^{\mathrm{a}} \pm 0.40$ & $289.17^{\mathrm{b}} \pm 0.01$ \\
$\beta$-carotene $(\mu \mathrm{g} / 100 \mathrm{~g})$ & $2.03^{\mathrm{a}} \pm 0.04$ & $18.13^{\mathrm{a}} \pm 0.02$ & $56.02^{\mathrm{b}} \pm 0.56$ \\
Ascorbic acid $(\mathrm{mg} / 100 \mathrm{~g})$ & $60.02^{\mathrm{a}} \pm 0.55$ & $57.03^{\mathrm{a}} \pm 0.25$ & $40.41^{\mathrm{a}} \pm 0.07$ \\
\hline
\end{tabular}

${ }^{1}$ Values are mean and \pm standard error of three separate determinations $(n=3)$.

${ }^{2}$ Values in the same row with different alphabet superscripts are significantly different $(p<0.05)$

${ }^{3}$ Dry matter content (Peel 18.9\%, Pulp 9.6\%, and seed 6.9\%)

${ }^{4}$ Fruit weight (average for one fruit) - 28.1g; Peel weight $-8.4 \mathrm{~g}(29 \%)$; Seed weight $5.6 \mathrm{~g}(16 \%)$; Juicy pulp - 15.4g (55\%) 


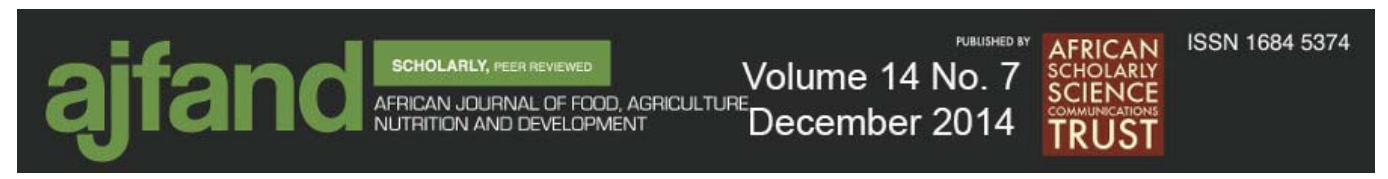

Table 2: Mineral content of Opuntia stricta fruit pulp and dried fruit ${ }^{1}$

\begin{tabular}{lcc}
\hline Minerals & $\begin{array}{c}\text { Fruit pulp } \\
(\mathrm{mg} / \mathrm{Kg})\end{array}$ & $\begin{array}{c}\text { Dried fruit } \\
(\mathrm{mg} / \mathrm{Kg})\end{array}$ \\
\hline Calcium & $12.80 \pm 0.23$ & $11.80 \pm 0.20$ \\
Iron & $38.00 \pm 0.29$ & $30.00 \pm 0.34$ \\
Magnesium & $3.61 \pm 0.12$ & $3.38 \pm 0.09$ \\
Sodium & $91.00 \pm 0.02$ & $88.00 \pm 0.03$ \\
Phosphorus & $622.00 \pm 0.40$ & $577.00 \pm 0.56$ \\
Zinc & $6.10 \pm 0.08$ & $4.70 \pm 0.06$ \\
Potassium & $4.50 \pm 0.00$ & $4.71 \pm 0.01$ \\
\hline
\end{tabular}

${ }^{1}$ Values are mean and \pm standard error of three separate determinations $(n=3)$ 


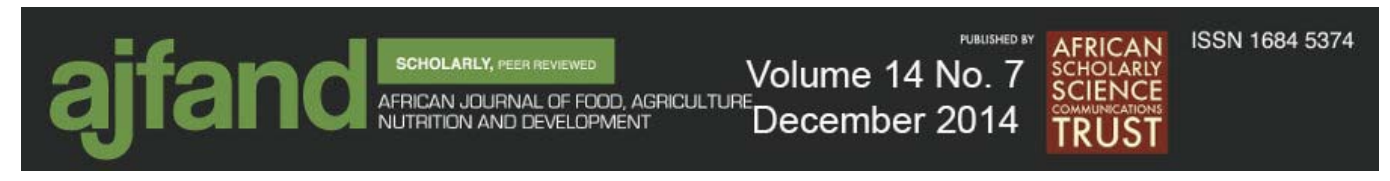

Table 3: Amino acid and Fatty acid profiles of Opuntia stricta fruit ${ }^{1,2,3}$

\begin{tabular}{|c|c|c|c|}
\hline Amino acids & Relative content $(\%)$ & Fatty acids & $\begin{array}{l}\text { Relative content } \\
(\%)\end{array}$ \\
\hline Isoleucine & $0.04 \pm 0.01$ & Linoleic acid (18:2) & $69.5 \pm 0.01$ \\
\hline Leucine & $0.07 \pm 0.01$ & Palmitic acid (16:0) & $12.5 \pm 0.04$ \\
\hline Lysine & $0.04 \pm 0.02$ & Oleic acid (18:1) & $12.3 \pm 0.03$ \\
\hline Cystine & $0.02 \pm 0.03$ & Stearic acid $(18: 0)$ & $4.20 \pm 0.02$ \\
\hline Methionine & $0.02 \pm 0.01$ & Capric acid (10:0) & $0.02 \pm 0.00$ \\
\hline Tyrosine & $0.12 \pm 0.15$ & Caprylic acid (8:0) & $0.01 \pm 0.02$ \\
\hline Phenylalanine & $0.05 \pm 0.03$ & $\begin{array}{l}\alpha \text {-Linolenic acid } \\
(18: 3)\end{array}$ & $0.70 \pm 0.04$ \\
\hline Threonine & $0.04 \pm 0.10$ & $\begin{array}{l}\text { Palmitoleic acid } \\
(16: 1)\end{array}$ & $0.70 \pm 0.00$ \\
\hline Tryptophan & $0.06 \pm 0.09$ & $\begin{array}{l}\text { Arachdonic acid } \\
(20: 4)\end{array}$ & $0.40 \pm 0.01$ \\
\hline Valine & $0.06 \pm 0.02$ & Myristic acid (14:0) & $0.20 \pm 0.31$ \\
\hline Histidine & $0.03 \pm 0.26$ & Lauric acid (12:0) & $0.04 \pm 0.02$ \\
\hline Arginine & $0.14 \pm 0.47$ & & \\
\hline Aspartic acid & $0.09 \pm 0.60$ & & \\
\hline Glutamic acid & $0.12 \pm 0.19$ & & \\
\hline Serine & $0.05 \pm 0.20$ & & \\
\hline Proline & $0.09 \pm 0.01$ & & \\
\hline Glycine & $0.06 \pm 0.00$ & & \\
\hline Alanine & $0.06 \pm 0.04$ & & \\
\hline
\end{tabular}

${ }^{1}$ Values are mean and \pm standard error of three separate determinations $(n=3)$

${ }^{2}$ Total essential amino acids $=0.52$, Total non-essential amino acids $=0.64$, Total sulfur containing amino acids $=0.19$, Total aromatic amino acids $=0.17$

${ }^{3}$ Unsaturation ratio $=(16: 1+18: 1+18: 2) /(12: 0+14: 0+16: 0+18: 0)$ 


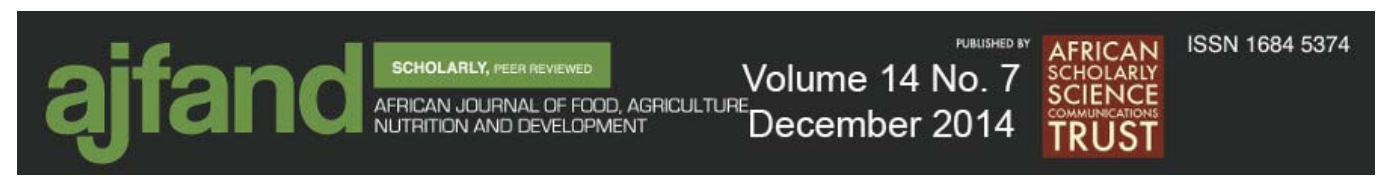

Table 4: Content of phytochemical compounds in whole Opuntia stricta fruits and their antioxidant properties ${ }^{1,2}$

\begin{tabular}{lccc}
\hline Bioactive compounds & Content & FRAP & DPPH \\
& $(\mathrm{g} / 100 \mathrm{~g})$ & $(\mu \mathrm{g} / \mathrm{mM} \mathrm{Fe} \mathrm{II})$ & $(\%)$ \\
\hline Total phenolics & $1.58^{\mathrm{a}} \pm 0.06$ & $4.03^{\mathrm{a}} \pm 0.23$ & $76.67^{\mathrm{a}} \pm 0.67$ \\
Flavonoids & $0.19^{\mathrm{b}} \pm 0.08$ & $1.22^{\mathrm{b}} \pm 0.01$ & $73.00^{\mathrm{a}} \pm 1.15$ \\
Tannins & $1.50^{\mathrm{a}} \pm 0.13$ & $6.90^{\mathrm{c}} \pm 0.09$ & $85.33^{\mathrm{b}} \pm 0.67$ \\
Phytates & $2.59^{\mathrm{a}} \pm 0.01$ & $4.83^{\mathrm{d}} \pm 0.08$ & $86.00^{\mathrm{b}} \pm 1.00$ \\
BHT & & $1.73 \pm 0.01$ & $97 \pm 0.31$ \\
\hline
\end{tabular}

${ }^{1}$ Values are mean and \pm standard error of three separate determinations $(n=3)$

${ }^{2}$ Values in the same column with different alphabet superscripts are significantly different $(p<0.05)$ 


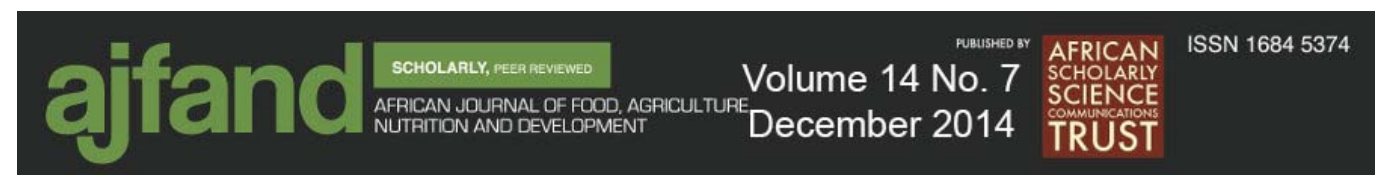

Table 5: Anti-diabetic activity of phytochemical compounds extracted from Opuntia stricta whole fruits ${ }^{1,2}$

\begin{tabular}{lll}
\hline Bioactive compounds & \multicolumn{1}{c}{$\begin{array}{c}\text {-Amylase inhibition } \\
(\%)\end{array}$} & \multicolumn{1}{c}{$\alpha$-Glucosidase inhibition } \\
& \multicolumn{1}{c}{$1 \%)$} \\
\hline Total phenolics & $0.00^{\mathrm{a}}$ & $79.00^{\mathrm{a}} \pm 2.08$ \\
Flavonoids & $0.00^{\mathrm{a}}$ & $36.67^{\mathrm{b}} \pm 1.02$ \\
Tannins & $15.67^{\mathrm{c}} \pm 0.33$ & $95.67^{\mathrm{c}} \pm 2.08$ \\
Phytates & $15.60^{\mathrm{cb}} \pm 0.11$ & $65.00^{\mathrm{d}} \pm 2.52$ \\
Acarbose & & $43.22^{\mathrm{acd}} \pm 0.89$ \\
\hline
\end{tabular}

${ }^{1}$ Values are mean and \pm standard error of three separate determinations $(n=3)$

${ }^{2}$ Values in the same column with different alphabet superscripts are significantly different $(p<0.05)$ 


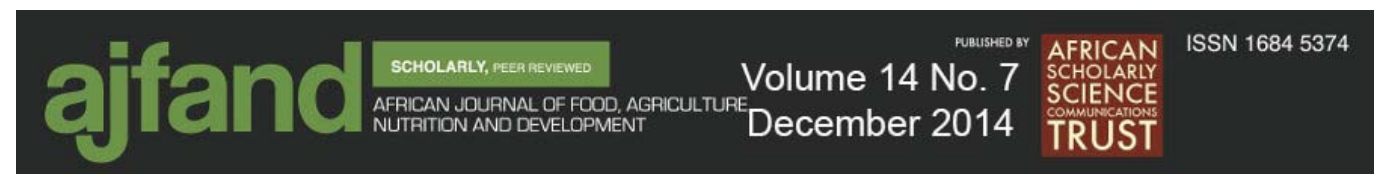

\section{REFERENCES}

1. Butera D, Tesoriere L, Di Gaudio F, Bongiorno A, Allegra M and AM Pintaudi Antioxidant activities of Sicilian prickly pear (Opuntia ficus-indica) fruit extracts and reducing properties of its betalains: Betanin and indicaxanthin. J. Agric. Food Chem. 2002; 50: 6895-6901.

2. Coria-Cayupán YS, Ochoa MJ and MA Nazareno Health-promoting substances and antioxidant properties of Opuntia sp. fruits. Changes in bioactive-compound contents during ripening process. Food Chem. 2011; 126: 514-519.

3. Moussa-Ayoub TE, El-Samahy SK, Rohn S and LW Kroh Flavonols, betacyanins content and antioxidant activity of cactus Opuntia macrorhiza fruits. Food Res Int. 2011; 44: 2169-2174.

4. Guzmán-Maldonado SH, Herrera-Hernández G, Hernández-Lopez D, Reynoso-Carmacho $R$, Guzmán-Tovar $A$, Vaillant $F$ and $P$ Brat Physicochemical, nutritional and functional characteristics of two underutilized fruit cactus species (Myrtillocactus) produced in central Mexico. Food Chem. 2010; 121: 381-386.

5. Piga A, Del Caro A, Pinna I and M Agabbio Changes in ascorbic acid, polyphenol content and antioxidant activity in minimally processed cactus pear fruits. LWT Food Sci Technol. 2003; 36: 257-262.

6. Russel CH and P Felker The prickly pears (Opuntia spp. Cactaceae). A source of human and animal food in semi-arid regions. Econ Bot. 1987; 41: 433-445.

7. Dominguez-Lopez A Use of the fruits and stems of the prickly pear cactus (Opuntia spp.) into human food. Food Sci Tech Int. 1995; 1: 65-69.

8. Ramadan MF and JT Morsel Oil cactus pear (Opuntia ficus-indica L.). Food Chem. 2003; 82: 339-345.

9. Chang S, Chiu-Lan H and Y Gow-Chin The protective effect of Opuntia dillenii Haw fruit against low-density lipoprotein peroxidation and its active compounds. Food Chem. 2008; 106: 569-575.

10. Kuti JO Antioxidant compounds from four Opuntia cactus pear fruit varieties. Food Chem. 2004; 85: 527-533.

11. Yahia EM and C Mondragon-Jacob Nutritional components and antioxidant capacity of ten cultivars and lines of cactus pear fruit (Opuntia spp.). Food Res Int. 2011; 44: 2311-2318. 


ajfand

12. Lee JC and KT Lim Effects of cactus and ginger extract as dietary antioxidants on reactive oxidant and plasma lipid level. Food Sci. Biotechnol. 2000; 9: 8388 .

13. VanderJagt TJ, Ghattas R, VanderJagt DJ, Crossey $M$ and RH Glew Comparison of the total antioxidant content of 30 widely used medicinal plants of New Mexico. Life Sci. 2002; 70: 1035-1040.

14. Kunyanga CN, Strum S, Graham S and JK Imungi Physico-chemical methods for preservation of Opuntia cactus fruit syrup: Empowerment of Maasai women in Laikipia, Kenya. Paper presented at the African Crop Science Society Conferenceon Science and Technology Supporting Food Security in Africa, Cape Town, South Africa, 2009.

15. AOAC. Official methods. Arlington, VA: Association of Official Analytical Chemists International, 2000.

16. Singleton VL, Orthofer R and RM Lamuela-Raventos Analysis of total phenols and other oxidation substrates and antioxidants by means of FolinCiocalteu reagent. Met Enzy. 1999; 299: 152-178.

17. Jia $\mathbf{Z}$, Mengcheng $\mathbf{T}$ and $\mathbf{J} \mathbf{W u}$ The determination of flavonoids contents in mulberry and their scavenging effects on superoxide radicals. Food Chem. 1999; 64: 555-559.

18. Price ML, Van Scoyoc S and LG Butler A critical evaluation of the vanillin reaction as an assay for tannin in sorghum grain. J Agric. Food Chem. 1978; 26: 1214-1217.

19. Latta $\mathbf{M}$ and M Eskin A simple and rapid colorimetric method for phytic acid determination. J Agric. Food Chem. 1980; 28: 1313-1315.

20. Sanchez-Moreno C, Larrauri JA and FA Saura-Calixto A procedure to measure the antiradical efficiency of polyphenols. Journal of the Science of Food and Agriculture 1998; 76: 270-276.

21. Pulido R, Bravo L and F Saura-Calixto Antioxidant activity of dietary polyphenols as determined by a modified ferric reducing/antioxidant power assay. J Agric. Food Chem. 2000; 48: 3396-3402.

22. Worthington V Worthington Enzyme Manual, Freehold, NJ: Worthington Biochemical Corporation, 1993: $36-261$.

23. Kader AA Cactus (prickly) pear: Recommendations for maintaining postharvest quality, 2002. Available from http://rics.ucdavis.edu/postharvest2/produce/Producefacts/Fruit/cactus.shml. Accessed on 30th November, 2013. 


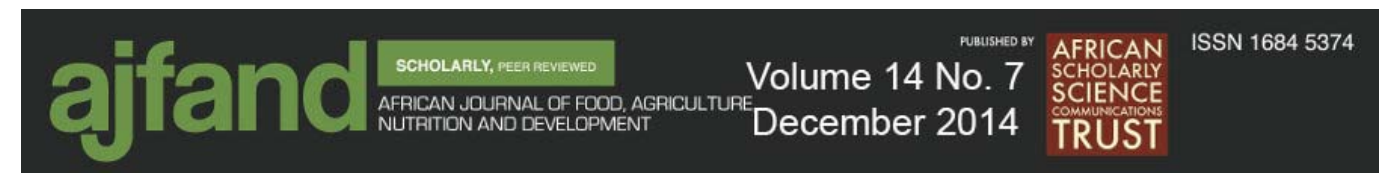

24. Sepulveda E and C Saenz Chemical and physical characteristics of prickly pear (Opuntia ficus-indica) pulp. Revista de Agroquimica y Tecnologia de Alimentos 1990; 30: 551-555.

25. USDA. 2010. Downloaded from http://www.mypyramind.gov/. Accessed on 8th October, 2013.

26. Ministry of Public Health Services [Kenya] and Save the Children UK, Report on Nutrition Situation in Kenya. Latest draft, May 2011.

27. Porte A, Rozende CM, Antunes OAC and LH Maia Amino acid reduction in processed (heated and alkalinized) pulps of bacuri (Platonia insignis Mart.), cupuacu (Theabroma grandiflorum Willd ex-Spreng Schum) and murici (Byrsonima crassifolici L.). Acta amaz. 2010; 40: 573-578.

28. FAO/WHO. Protein quality evaluation. Reports of a Joint FAO/WHO Expert Consultation. Food and Agriculture Organization of the United Nations. Rome, Italy, 1991.

29. Tan C and YB Che Man Differential scanning calorimetric analysis of edible oils: comparison of thermal properties and chemical composition. J Am Oil Chem Soc. 2000; 77: 143-155.

30. Kunyanga CN, Imungi JK, Okoth M, Momanyi C, Biesalski HK and V Vadivel Antioxidant and antidiabetic properties of condensed tannins in acetonic extract of raw and processed food ingredients from Kenya. J Food Sci. 2011a; 76: 560-567.

31. Kunyanga CN, Imungi JK, Okoth MW, Biesalski HK and V Vadivel Antioxidant and type II diabetes related functional properties of phytic acid extract from Kenyan indigenous food ingredients: Effects of traditional processing methods. Eco. Food Nutr. 2011b; 50: 452-471. 